\title{
ANALISA EFEKTIVITAS ALAT PENUKAR KALOR JENIS SHELL AND TUBE HASIL PERENCANAAN MAHASISWA SKALA LABORATORIUM
}

\author{
Saut Siagian \\ Program Studi Teknik Mesin \\ Fakultas Teknik, UPN "Veteran" Jakarta, Jakarta Selatan, Indonesia \\ email: saut.siagian100753@gmail.com
}

\begin{abstract}
Heat exchanger is a means of heat transfer from the fluid temperature is higher to a fluid other temperature is lower, in which the heat exchanger is one tool that is often found in industries such as thermal power plant, machinery chemical processes, equipment air conditioner, refrigerator, radiators etc. The design of the exchanger draw string shell and tube is planned using two fluids are cold fluid (water) in tempratur $\left(T_{c o}=37^{\circ} \mathrm{C}\right.$ ) with a flow rate past the fluid ( $\mathrm{mc}=0.122 \mathrm{~kg} / \mathrm{s}$ ) and the hot fluid (oil) on tempratur (Thi $=47^{\circ} \mathrm{C}$ ) with a flow rate past the fluid (mh $=0.075 \mathrm{~kg}$ / s) in which the operation of Heat exchanger will be operated on a thermal load constant that is equal to 5100 watts, then in in the planning of found the number of tube of Heat exchanger was 37 pieces with effectiveness of Heat exchanger result of the design is $62 \%$.
\end{abstract}

Keywords: Heat exchanger, shell and tube, constant thermal loads

\section{PENDAHULUAN}

Alat penukar kalor ini mempunyai peran yang penting dalam suatu proses produksi dalam industry salah satu tipe darialat penukar kalor (APK) yang banyak dipakai adalah shell and tube heat exchanger.Alat ini terdiri dari sebuah shell silindris dibagian luar dan sejumlah tube pada bagiandalam, sedangkan untuk mendistribusikan fluida kerja didalam sistem baik fluida panasataupun fluida dingin, maka dipilihlah dalam kegiatan penelitian perancangan APK ini mengunakan dua buah pompa yaitu jenis gear pump untuk mensirkulasikan fluida panas (oil) dan jenis pompa sentrifugal untuk mensirkulasikan fluida dingin (water) yang berfungsi untuk mensirkulasikan kedua fluida tersebut sehingga dalam penentuan yang tepat terhadap spesifikasi dari alat penukar kalor yang dirancang diharapkan dapat meningkatkan performance dari APK yang dirancang oleh mahasiswa tersebut.

Aplikasi Shell \& Tube Heat Exchanger

Shell \& tube Heat Exchanger biasanya digunakan lebih luas pada industri dengan sistem produksi industri melibatkan proses kimia, kususnya pada industri penyulingan, karena banyak sekali keuntungan yang dapat dihasilkan dalam penggunan heat exchanger tipe shell \& tube. Untuk standar konstruksi dan penggunaan heat exchanger penulis menggunakan standar TEMA (Tubular Exchanger Manufactures Association), selain itu penulis juga menggunakan standar ASME untuk pemilihan bahan dan kalkulasi bejana tekan.

Keunggulan Shell \& Tube Heat Exchanger

Ada beberapa keuntungan dari Shell \& tube heat exchanger:

1. Kondensasi atau boiling heat transfer. Dapat dengan mudah diakomodasikan dari Shell dan Tube Heat Exchanger.

2. Presure Drop dapat divariasikan sesuai dengan kapasitas heat exchanger.

3. Termal stress dapat ditekan

4. Pemilihan bahan atau pemilihan material dapat divariasikan.

5. Untuk meningkatkan heat transfer maka dapat digunakan fins (sirip) pada Tube.

6. Perawatan lebih relatif lebih mudah karena dapat di bongkar-pasang.

Shell dan tube merupakan suatu jenis heat exchanger yang banyak digunakan pada berbagai bidang industri yang diantaranya berkerja pada sistem refrigerasi dan tata udara karena bentuknya yang ringkas (compact) dan ringan. Pada umumnya fluida cair mengalir sepanjang pipa dan gas mengalir pada saluran diantara fin. Salah satu hal penting yang perlu diperhatikan dalam heat exchanger adalah perpindahan panasnya

Defenisi panas adalah energy yang ditransfer akibat dari pada perbedaan temperatur. Pengertian diatas 
adalah berdasarkan prinsip termodinamika. Walaupun hukum termodinamika menelaah transfer energy, metode ini hanya dapat menganalisa suatu sistem yang dalam keadaan setimbang. Sehingga dapat diperhitungkan jumlah energy yang diperlukan untuk merubah suatu sistem dari suatu keadaan kesetimbangan ke kesetimbangan lain, tetapi hukum termodinamika tidak dapat menganalisa bagaimana kecepatan perubahan itu terjadi.

Pemanasan batangan baja dalam air panas. Hukum termodinamika dapat digunakan untuk menentukan temperature akhir sesudah kedua sistem mencapai kesetimbangan dan jumlah energy yang ditransfer dapat dihitung dari keadaan mula-mula dan pada keadaan akhir kesetimbangan, tetapi tidak dapat menjelaskan bagaimana kecepatan panas itu ditransfer dan tidak dapat menjelaskan berapa lama waktu yang diperlukan untuk mencapai temperature tertentu yang diinginkan?

Untuk analisa transfer panas yang sempurna, maka perlu memahami tiga mekanisme transfer panas yaitu :
1. Konduksi
2. Konveksi
3. Radiasi

Konduksi adalah suatu metode transfer panas hanya dengan media padat. Bila pada suatu benda terdapat Gradien Temperatur, maka panas akan ditransfer dari daerah temperature yang lebih tinggi ke daerah temperature yang lebih rendah.

Bila suatu fluida berkontak dengan permukaan zat padat pada temperature yang berbeda, maka hasil dari proses pertukaran energy termis itu disebut transfer panas secara konveksi.

Kebanyakan masalah transfer panas sangat kompleks, maka praktis tidak mungkin memperhitungkan seluruh factor-faktor seperti : diameter pipa, kecepatan

\section{PERKEMBANGAN SERTA PENGGUNAAN DALAM DUNIA INDUSTRI}

Sejak menggulirnya isu global akan menipisnya cadangan energi fosil di dunia dewasa ini, mendorong pengguna energi terutama yang mengkomsumsi energi dalam skalar besar untuk mengantisipasinya dengan membenahi system thermalnya.
Perkembangan industri terutama pada bidang teknologi banyak dibutuhkan suatu alat untuk memindahkan sejumlah energi panas dari sistem ke lingkungan atau antara bagian-bagian yang berbeda di dalam sistem. Heat Exchanger adalah peralatan yang digunakan untuk melakukan proses pertukaran kalor antara dua fluida, baik cair ( panas atau dingin ) maupun gas, dimana fluida ini mempunyai temperatur berbeda.

Heat Exchanger banyak digunakan di berbagai industri tenaga atau industry lainnya dikarenakan mempunyai beberapa keuntungan, antara lain :

1.Konstruksi sederhana dan kokoh.

2.Biaya yang digunakan relatif murah.

3. Kemampuannya untuk bekerja pada tekanan dan temperatur yang tinggi dan tidak membutuhkan tempat yang luas.

Dikarenakan ada banyak jenis penukar kalor, maka alat penukar kalor dapat dikelompokkan menjadi beberapa bagian:

\section{Concentric Tube.}

2. Shell and Tube.

\section{Compact Heat Exchanger.}

Jenis dariconcentric tube heat exchanger berupa dua buah pipa yang tersusun secara konsentris dimana aliran yang mengalir berupa aliran pararel serta fluida yang digunakan di dalam concentric tersebut adalah fluida panas dan dingin. Fluida panas dan dingin masuk pada ujung yang sama, dan juga keluar pada ujung yang sama juga.

Tipe aliran keduanya adalah tipe aliran counter yang dimana fluida panas dan fluida dingin mengalir pada arah yang berlawanan.Penukar Panas, khususnya jenis shell-and-tube, merupa kan peralatan yang banyak dipergunakan di berbagai bidang industri, seperti perminyakan, petrokimia, energi dan lain sebagainya. Fungsi alat penukar panas, sebagaimana namanya, adalah untuk memindahkan panas dari satu fluida ke fluida yang lainnya. Salah satu parameter yang menentukan pemilihan suatu jenis penukar 
panas adalah kemampuannya untuk memindahkan panas, yang pada umumnya disebut efektivitas. Untuk satu ukuran penukar panas tertentu, efektivitas yang tinggi menunjukkan semakin banyaknya fluks panas yang dapat dipindahkan per satuan massa fluida. Sehingga upaya untuk mengembangkan suatu rancangan penukar panas yang memberikan efektivitas perpindahan panas tinggi senantiasa menjadi topik litbang di berbagai lembaga riset, universitas ataupun industri di dunia.

Dilatar belakangi oleh keinginan untuk memperoleh rancangan penukar panas shelland-tube yang memiliki keunggulan kinerja dan untuk mengembangkan kemampuan di bidang rekayasa dan rancang bangun alat penukar panas, khususnya jenis shell-and-tube,

- Eksperimen skala laboratorium untuk mempelajari dinamika aliran dan mem peroleh korelasi koefisien per pindahan panas serta rugi tekanan.

\section{METODE PENELITIAN}

Metode yang di pakai dalam kegiatan penelitian ini yaitu dengan cara melakukan analisa perencanaan spesifikasi disain dari APK yang akan dirancang,kemudian dilakukan analisa perencanaan perhitungan terhadap spesifikasi disain tersebut sehingga didapatkan nilai hasi lrancangan dari APK tersebut kemudian dilakukan perencanaan pembuatan APK skala laboratorium sesuai dengan analisa disain hasil perencanaan perhitungan. Berikut diagram alir kegiatan penelitian yang kami lakukan.

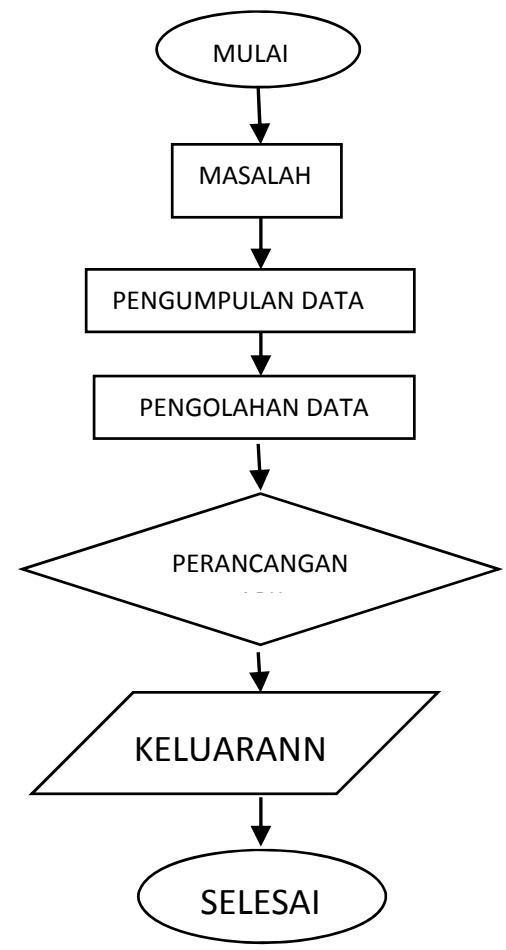

Gambar 1. Digram alir kegiatan penelitian

\section{HASIL DAN PEMBAHASAN}

Dalam kegiatan penelitian ini akan dilakukan terlebih dahulu penentuan spesifikasi disain dari alat seperti terlihat pada Tabel 1, yang kemudian dilakukan analisa perencanaan perhitungan disandari APK jenis shell and tube skala laboratorium.

Tabel 1. Spesifikasi disain alat penukar jenis shell and tube

\begin{tabular}{|l|l|}
\hline \multicolumn{1}{|c|}{ Spesifikasi Disain APK } & \multicolumn{1}{c|}{ Shell and tube } \\
\hline Diameter tube (OD) & $0,0127 \mathrm{~mm}$ \\
\hline Panjang tube (L) & $0,6 \mathrm{~m}$ \\
\hline Laju alir fluida masuk shell (mh) & $0,075 \mathrm{~kg} / \mathrm{s}$ \\
\hline Laju aliran fluida masuk tube (mc) & $0,122 \mathrm{~kg} / \mathrm{s}$ \\
\hline Temp.fluidadingin masuk tube (Tci) & $27^{\circ} \mathrm{C} / 300 \mathrm{~K}$ \\
\hline Temp. fluidadingin keluar tube (Tco) & $37^{\circ} \mathrm{C} / 310 \mathrm{~K}$ \\
\hline Temp. fluida panas masuk shell (Thi) & $47^{\circ} \mathrm{C} / 320 \mathrm{~K}$ \\
\hline
\end{tabular}

Sumber : Hasil Rancangan Mahasiswa.

1. Perencanan perhitungan spesifikasi disain alat penukar kalor.

1.1. Perhitungan besarnya aliran energi panas yang diterima oleh air pendingin dapat dihitung dengan persamaan :

$\mathrm{Q}_{\mathrm{C}}=\mathrm{m}_{\mathrm{c}} \times \mathrm{C}_{\mathrm{p} . \mathrm{c}}\left(\mathrm{T}_{\mathrm{co}}-\mathrm{T}_{\mathrm{ci}}\right)$

Sehingga nilai Qc didapatkan nilai sebesar 5100Watt. 
1.2. Perhitungan besarnya aliran energi panas yang dilepas oleh fluida panas dapat dihitung dengan persamaan berikut :

$\mathrm{Q}_{\mathrm{h}}=\mathrm{m}_{\mathrm{h}} \times \mathrm{C}_{\mathrm{P} . \mathrm{h}}\left(\mathrm{T}_{\mathrm{h} . \mathrm{o}}-\mathrm{T}_{\mathrm{h} . \mathrm{i}}\right)$

atau

$\mathrm{T}_{\mathrm{h} . \mathrm{o}}=\mathrm{T}_{\mathrm{h} . \mathrm{i}}-\frac{Q h}{m h . C p h}$

Maka dengan mengunakan (pers 3)untuk rencana temperatur fluida panas (oli) yang keluar dari sisi shell adalah sebesar 303,8 K

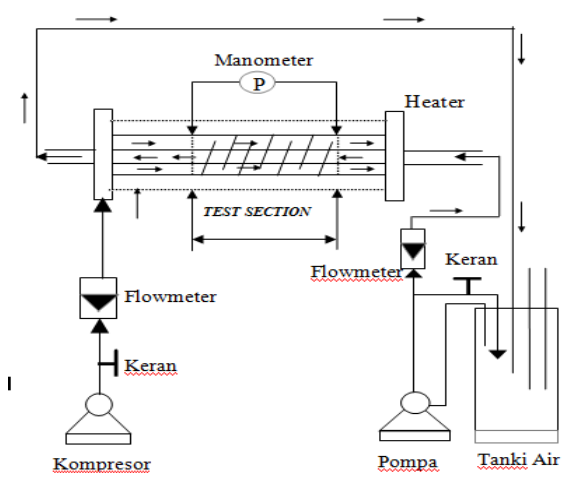

Gambar 2.Sistem alat penukar kalor yang sedang dirancang.

1.3. Sedangkan untuk perencanaan perhitungan beda temperature rata-rata kedua fluida dari APK:

$$
\Delta \mathrm{T}_{\mathrm{m}}=\frac{\Delta T 1-\Delta T 2}{\ln \frac{\Delta T 1}{\Delta T 2}}
$$

dimana nilai $($ Thi $)=320 \mathrm{~K}$ dan $($ Tho $)=303,8 \mathrm{~K}$, sedangkan untuk $(\mathrm{Tci})=300 \mathrm{~K}$ dan $(\mathrm{Tco})=310 \mathrm{~K}$, maka beda temperature rata-rata kedua fluida adalah sebesar 6,4 K. Dimana koefesien perpindahan panas menyeluruh (U) dari alat penukar kalor yang akan menjadi objek studi adalah sebesar $\mathrm{U}=350-900 \mathrm{~W} / \mathrm{m}^{2} \mathrm{~K}$ (water to lubrican oil), sehingga dalam perencanaan ini dipilih nilai harga maksimal yaitu sebesar $900 \mathrm{~W} / \mathrm{m}^{2} \mathrm{~K}$.

1.4. Perencanaan perhitungan luas bidang perpindahan panas dari APK.

$\mathrm{Q}=\mathrm{A} \cdot \mathrm{U} \cdot \Delta \mathrm{T}_{\mathrm{m}}$ atau

$\mathrm{A}=\frac{Q}{U . \Delta T m}$

Sehingga ;

$$
\begin{aligned}
\mathrm{A} & =\frac{5100 \mathrm{Watt}}{900 \frac{\mathrm{W}}{\mathrm{m}} \cdot \mathrm{K} \cdot 64 \mathrm{~K}} \\
& =0,88 \mathrm{~m}^{2}
\end{aligned}
$$

Maka untuk jumlah tube pada alat penukarkalor yang akan dirancang dapat diketahui dengan persamaan (5) yaitu

$$
\begin{aligned}
\mathrm{N} & =\frac{A}{\pi D . l} \\
& =\frac{0,88}{\pi \cdot 0,0127.0,6} \\
& =37 \text { Tube }
\end{aligned}
$$

1.5 .Maka untuk perencanaan diameter shell dari alat penukar kalor yang akan dirancang adalah sebagai berikut:

$\mathrm{D}=0,63 \sqrt{\frac{c l}{C T}} \times\left(\mathrm{A} \times(\mathrm{PR})^{2} \times \mathrm{d}_{\mathrm{o}} / 1\right)^{1 / 2}$

maka diameter shell didapatkan nilai sebesar 0,112 $\mathrm{m}$

\section{EFEKTIVITAS.}

Parameter efektivitas Alat Penukar Kalor menggambarkan besarnya laju perpindahan panas actual dibagi dengan laju perpindahan panas maksimum yang mungkin terjadi pada Alat Penukar Kalor. Laju perpindahan panas actual pada APK adalah besar panas yang dipindahkan dari sisimassa dan konservasi energy, besarnya laju perpindahan panas actual pada Alat Penukar Kalor dapat dihitung dengan persamaan dibawah ini.

$$
\mathrm{Q}=\text { U.A.LMTD }
$$

Dimana :

$\mathrm{Q}$ = laju perpindahan panas actual pada Alat Penukar Kalor ( w )

$\mathrm{U}=$ Koefisien perpindahan panas menyeluruh $\left(\mathrm{w} / \mathrm{m}^{2} \mathrm{~K}\right)$

$\mathrm{A}=$ luas permukaan perpindahan panas $\left(\mathrm{m}^{2}\right)$

LMTD $=$ Log Mean Temperature difference beda temperature ) ( $\mathrm{K}$ )

Nilai LMTD adalah nilai yang berkaitan dengan beda temperatur antara sisi panas dengan sisi dingin, dengan asumsi bahwa aliran pendingin mengalir dalam kondisi tunak ( Steady flow), tidak 
ada kehilangan panas secara keseluruhan, tidak ada perubahan fase pendingin, maka nilai LMTD dapat dihitung dengan menggunakan persamaan ;

$$
\Delta \mathrm{T}_{\mathrm{m}}=\mathrm{LMTD}=\frac{\left(\mathrm{T}_{\mathrm{wm}}-\mathrm{T}_{\mathrm{in}}\right)-\left(\mathrm{T}_{\mathrm{wm}}-\mathrm{T}_{\text {out }}\right)}{\ln \frac{\left(\mathrm{T}_{\mathrm{wm}}-\mathrm{T}_{\mathrm{in}}\right)}{\left(\mathrm{T}_{\mathrm{wm}}-\mathrm{T}_{\text {out }}\right)}}
$$

Dimana :

$\mathrm{T}_{\mathrm{h} . \text { in }}=$ Temperatur fluida panas pada sisi masuk

$\mathrm{T}_{\mathrm{h} \text { out }}=$ Temperatur fluida panas pada sisi keluar

$\mathrm{T}_{\mathrm{C}, \mathrm{in}}=$ Temperatur fluida dingin pada sisi masuk

$\mathrm{T}_{\mathrm{c} \text {.out }}=$ Temperatur fluida dingin pada sisi keluar

Tahap selanjutnya perencanaan perhitungan nilai efektifitas dari APK yang akan dirancang adalah sebagai berikut:

$\mathcal{E}=\frac{1-\exp (-N T U X(1-C *)}{1-C * \exp (-N T U \times(1-C *)}$

dimana :

$$
\begin{aligned}
\Delta \mathrm{T}_{\max } & =\mathrm{T}_{\text {hi }}-\mathrm{T}_{\mathrm{ci}} \\
& =320 \mathrm{~K}-300 \mathrm{~K} \\
& =20 \mathrm{~K}
\end{aligned}
$$

Sedangkan untuk heat capacity adalah sebesar:

$\mathrm{C}_{\mathrm{C}}=\mathrm{m}_{\mathrm{c}} \times \mathrm{C}_{\mathrm{pc}}=0,3 \times 4179=503,8 \mathrm{~J} / \mathrm{s} \mathrm{K}$

$\mathrm{C}_{\mathrm{h}}=\mathrm{m}_{\mathrm{h}} \times \mathrm{C}_{\mathrm{p} . \mathrm{h}}=0,075 \times 4180=313,5 \mathrm{~J} / \mathrm{s} \mathrm{K}$

Sedangkan nilai $C^{*}$ dapat dihitung dengan

menggunakan persamaan :

$$
\begin{aligned}
\mathrm{C}^{*} & =\frac{C \min }{C \max } \\
& =\frac{313,5}{503,8} \\
& =0,62
\end{aligned}
$$

Sehingga untuk nilai $\mathrm{Q}_{\max }$

$\mathrm{Q}_{\max }=\mathrm{C}_{\min } \Delta \mathrm{T}_{\mathrm{m}}=313,5.20=6270 \mathrm{Watt}$
Sehingga nilai perpindahan panas yang diterima oleh fluida pendingin adalah sebagai berikut

$\mathrm{Q}_{\mathrm{c} \cdot \max }=\mathrm{Q}_{\max }=\mathrm{C}_{\mathrm{c}} \cdot\left(\mathrm{T}_{\mathrm{co.max}}-\mathrm{T}_{\mathrm{ci}}\right)$

$6270=313,5 \times\left(\mathrm{T}_{\mathrm{CO} \max }-300\right)$

$\mathrm{T}_{\text {co.max }}=312,4 \mathrm{~K}$

Sedangkan untuk nilai NTU adalah sebagai berikut:

$$
\begin{aligned}
\mathrm{NTU} & =\frac{U . A}{C \min } \\
& =\frac{900 \times 0,88}{313,5} \\
& =2,5
\end{aligned}
$$

Maka untuk nilai efektifitas dari alat penukar kalor yang akan dirancang adalah sebagai berikut

$$
\begin{aligned}
\mathcal{E} & =\frac{1-\exp (-N T U X(1-C *)}{1-C * \exp (-N T U \times(1-C *)} \\
& =\frac{1-\exp (-2,5 \times(1-0,62)}{1-0,62 \exp (-2,5(1-0,62)} \\
& =0.61
\end{aligned}
$$

Sehingga efektifitas dari alat penukar kalor hasil rancangan adalah sebesar $61 \%$.

\section{KESIMPULAN}

Bahwa dalam kegiatan penelitian pembuatan alat penukar kalor dengan kapasitas sebesar 5100 Watt didapatkan jumlah tube sebanyak37 buah dengan nilai efektifitas APK hasilran cangan yaitu sebesar $62 \%$.

\section{DAFTAR PUSTAKA}

(1) Ramesh K. Sahah and Dusan P Sekulic2003. Fundamentals of Heat Exchenger Desing. John Wiley \& Son,INC.Hoboken, New Jersey.

(2) Ricahard. C. Byrne. 2000. Standard ofthe Turbular Excharnger ManufacturesAssociation, standards of the Turbular Exchanger Manufacture Assocition,INC. New York,. 
(3) Keith Escoe, A., Mechanical Design ofProcess Systems, vol. 2, Gulf Pub.Company, Houston Texas, 1986.

(5) Soekardi. C. April 2001. Prediksi karakteristik termal sebuah penukarkalor dampak pemilihan faktorpengotoran konstan, Poros, 4 No 2, 141-150.

(6) Soekardi.C. April 2002. Implikasi Perancangan Sebuah penukar kalor dengan faktor Pengotoran dan fungsi waktu terhadap kinerjanya pada kondisi operasi beban thermal konstan, Poros,Vol. 5. NO. p. 129-137.

(7) Thurmarimurungan M. 2006. Performance Analysis of Shell and Tube Heat Exchanger Using Miscedle System. American Journal of Applied Sciences.

(8) Yulianto S. 2010. Analisa Perancangan Alat Pendingin Jenis Shell And Tube Dengan Cleaning Interval yang Bervariasi. Tesis Program Studi Teknik Mesin Universitas Pancasila 